basin in Spain and the Asi basin in Lebanon and Syria. Environ. Res. Lett. 10, 114016 (2015)

\section{Personalized diets for health}

People who eat identical meals display different blood glucose levels afterwards, thanks in part to differences in their gut microbes.

Large spikes in blood glucose after eating increase the risk of type 2 diabetes, so dietary guidelines rank foods based on their glycaemic index - an indicator of their effects on blood glucose. Eran Elinav and Eran Segal of the Weizmann Institute of Science in Rehovot, Israel, and their colleagues

continuously monitored

$\frac{1}{z}$ the diets and lifestyles of 800 people over a week, and found that meals with the same glycaemic index caused widely different glucose levels in participants. By analysing data on the participants' gut microbiomes, physical activity and other clinical factors, the team created personalized diets for 26 people and found that these resulted in lower glucose levels after meals than did non-personalized diets.

The study could partly explain the limited efficacy of universal dietary guidelines, the authors say.

Cell 163, 1079-1094 (2015)

\section{QUANTUM METROLOGY}

\section{Lasers reveal quantum jitters}

Ultrafast laser pulses can be used to detect the motion of a single atom, from energetic wiggles to quantum jitters.

Kale Johnson at the University of Maryland in College Park and his colleagues trapped ions of ytterbium and zapped them with laser pulses just 10 picoseconds long. The pulses gave the atom small kicks in momentum of different magnitudes, depending on its internal state. This resulted in a new state that encoded the atom's original motion. After another sequence of pulses, the researchers observed fluorescent light from the atom that allowed them to measure its quantum motion.

The technique could be useful for future quantum computers built from trapped ions, the team says.

Phys. Rev. Lett. 115, 213001 (2015)

\section{BIOELECTRONICS}

\section{Flower given digital power}

Researchers have incorporated electronic circuitry into the tissues of a rose.

Magnus Berggren at Linköping University in Norrköping, Sweden, and his colleagues submerged the cut end of a rose stem into a water-based solution of PEDOT, a conducting polymer that is used in printable electronics. Capillary action pulled the polymer up into the rose's vascular tissue, where it came out of solution and selfassembled into wires, some as long as 10 centimetres. By attaching gold probes coated with PEDOT to the wires, the researchers made individual transistors and demonstrated a simple digital circuit. The transistors' electrical performance was on a par with that of conventional printed PEDOT circuits.

The technology could eventually be used to record or regulate plant physiology, the authors say.

Sci. Adv. 1, e1501136 (2015)

\section{AGRICULTURAL ECOLOGY}

\section{Complex effects of pesticides on bees}

Honeybee colonies could be compensating for the harmful effects of certain pesticides by producing more workers, at least in the short term.

Some European countries banned neonicotinoid pesticides in 2013, but this \section{SOCIAL SELECTION}

\section{Text-mining block prompts response}

A scientist who mines the text of research publications was blocked by the scientific publisher Elsevier from downloading large numbers of its papers - a move that he described in a blog post that was shared by many on social media. Chris Hartgerink, a statistician at Tilburg University in the Netherlands, says that the publisher is hindering his research. Elsevier allows text-mining through the use of a specific application programming interface, and says that this prevents its website from being slowed down by researchers who download large amounts of data. Frank Huysmans, a library scientist at the University of Amsterdam, linked to the blog post on $\checkmark$ NATURE.COM Twitter: "How signing away copyright to For more on popular papers: go.nature.com/pkmigd academic publishers obstructs content mining research ... Strong case for \#openaccess \#tdm." remains controversial because field studies have failed to confirm the adverse effects reported for bees in the lab. Mickaël Henry at the French National Institute of Agricultural Research in Avignon and his colleagues positioned honeybee colonies in farmers' fields so that they were exposed to varying levels of the pesticide thiamethoxam. The team radio-tagged and monitored nearly 7,000 bees, and found that pesticide exposure caused an acceleration in death rate over time.

The colonies, however, compensated for dead foragers by producing more workers and fewer drones. This maintains honey production but could decrease bee reproduction in the long term. The risks of pesticides in the field may be best understood by studying entire colony cycles, the authors say.

Proc. R. Soc. B 282, 20152110 (2015)

\section{PLANETARY SCIENCE \\ Martian moon will break apart}

Phobos, one of Mars's two moons, will disintegrate some 20 million to 40 million years

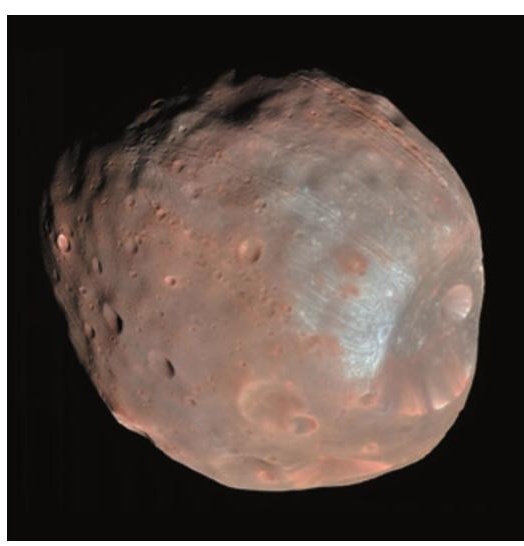

from now, and its particles will form the only planetary ring in the inner Solar System.

Benjamin Black and Tushar Mittal of the University of California, Berkeley, made these predictions by analysing tidal and other forces that are currently pulling Phobos (pictured) towards Mars. Using a geological model of how rock holds together, they calculated that the moon would rip apart before it smashed into the planet. The resulting ring would be stable for 1 million to 100 million years, they say.

Nature Geosci. http://dx.doi. org/10.1038/ngeo2583 (2015)

\section{$\rightarrow$ NATURE.COM}

For the latest research published by Naturevisit:

www.nature.com/latestresearch 